\title{
Children's hospitalizations with a mood disorder diagnosis in general hospitals in the united states 2000-2006
}

Tamar Lasky ${ }^{1 *}$, Aliza Krieger ${ }^{2}$, Anne Elixhauser ${ }^{3}$ and Benedetto Vitiello ${ }^{4}$

\begin{abstract}
Background: Mood disorders including depression and bipolar disorders are a major cause of morbidity in childhood and adolescence, and hospitalizations for mood disorders are the leading diagnosis for all hospitalizations in general hospitals for children age 13 to 17 . We describe characteristics of these hospitalizations in the U.S. focusing on duration of stay, charges, and geographic variation.

Methods: The Kids' Inpatient Database was analyzed to calculate hospitalization rates for 2000, 2003, and 2006. For each year, information was available for over 2 million hospitalizations, representing 6.3 to 6.5 million hospital stays annually in acute care, non-psychiatric hospitals.

Results: The rate of pediatric hospitalizations with a principal diagnosis of a mood disorder was 12.4/10,000 in 2000, 13.0 in 2003, and 12.1 in 2006. In the same period, the incidence of hospitalizations for depressive disorders decreased from 9.1 to 6.4/10,000 children while the incidence of hospitalizations for bipolar disorders increased from 3.3 to 5.7/10,000 children. The mean length of stay increased from 7.1 to 7.7 days, while inflation-adjusted hospital charges increased from $\$ 10,600$ in 2000 , to $\$ 13,700$ in 2003 , to $\$ 16,300$ in 2006. The proportion of mood disorder stays paid by government increased from $35.3 \%$ to $45.2 \%$. The Western region experienced the lowest rates $(9.9 / 10,000,11.6$ and 10.2 in 2000, 2003 and 2006) while the Midwest had the highest rates (26.4, 27.6, and 25.4).
\end{abstract}

Conclusions: Mood disorders are a major reason for hospitalization during development, especially in adolescence. Mood disorder hospitalizations remained relatively constant from 2000-2006, but diagnoses of depressive disorders decreased while diagnoses of bipolar disorders increased. Hospitalization rates vary widely by region of the country.

\section{Background}

The impact of mood disorders in children has been described with respect to morbidity and mortality, with reports that, by age $18,14.3 \%$ of adolescents will have experienced a mood disorder, that depression affects 1$2 \%$ of children 6-12 years old and 4-6\% of adolescents 13-17 years old over a 12-month period, that depression is a primary risk factor for suicide, which is the third leading cause of death in adolescence, and that bipolar disorders have been increasingly diagnosed among children and adolescents [1-5]. While mood disorders in

\footnotetext{
* Correspondence: tlasky@mie-epi.com

${ }^{1}$ MIE Resources, Kingston, Rhode Island, USA

Full list of author information is available at the end of the article
}

children are widely recognized to be associated with utilization of a full range of outpatient mental health services, it is less widely recognized that mood disorders are one of the leading diagnoses associated with children's admissions to general hospitals. In the United States, mood disorders were the second most frequent primary discharge diagnoses at age 10-14, and ranked first at age 15-17 out of all children's hospitalizations in general hospitals in 2000 [6,7]. We here report on the most recent trends in the rate of mood disorder hospitalizations in general non-psychiatric hospitals in the U.S. with the purpose of further documenting the relevance of these common disorders to child health.

Efforts to describe the burden of mental health conditions in children in the United States and the resources
C Biomed Central

(c) 2011 Lasky et al; licensee BioMed Central Ltd. This is an Open Access article distributed under the terms of the Creative Commons Attribution License (http://creativecommons.org/licenses/by/2.0), which permits unrestricted use, distribution, and reproduction in any medium, provided the original work is properly cited. 
used to address this burden must rely on a variety of data sources reflecting the breadth of mental health services used to care for children with mental health problems [8]. Mental health services are provided in specialty mental health facilities, the general medical/ primary care sector, the human services sector including schools and criminal justices systems, and through voluntary support networks [8]. Within the de facto mental health system, care is divided into public and private sectors with the public sector including federal and state resources, and the private sector including services operated by private agencies or financed with private resources. In 2003, public sources financed more than half of all spending for mental health in the U.S, with costs for inpatient services accounting for about one fourth of total mental health expenditure [9]. Hospitalization takes place in both specialty mental health facilities and general hospitals and covers a range of situations, from short term emergency management to long term institutionalization. Most hospitalizations for mental health occur in the non-specialty general hospitals in the U.S. [9].

Within this complex array of services, admissions to general hospitals are documented in a government run national probability-based sample of hospital stays through the Healthcare Cost and Utilization Project (HCUP) Kids' Inpatient Database (KID) that is released every three years. Researchers have used hospital discharge databases to describe children's hospitalizations for any psychiatric or mental health diagnoses, for intentional self-inflicted injuries, and for diagnoses of autism and attention-deficit hyperactivity disorder in the US [10-13]. Our analysis focuses on mood disorders because they are the largest category within hospitalizations with a mental health diagnosis in the database, and are the leading diagnosis associated with hospitalizations for children 15-17 of any diagnosis. By definition, the analyses presented here exclude hospitalizations with primary diagnoses of other mental health conditions such as: anxiety, somatoform, dissociative and personality disorders, schizophrenia, psychosis or substance related mental disorders.

The following questions were addressed: What was the rate of hospitalizations for children with a diagnosis of mood disorder over this period? How did the incidence of hospitalizations with depressive disorders vs. bipolar disorders change during this period? What were the patient and hospital characteristics of these hospitalizations with regards to age, gender, payer, charges and length of stay? What proportion of hospitalizations for mood disorders was associated with self-injurious/suicidal behavior? How did the incidence of children's hospitalizations for mood disorders vary in regions across the U.S.?

\section{Methods}

The Kids' Inpatient Database (KID) is one in a family of databases and software tools developed as part of the Healthcare Cost and Utilization Project (HCUP), a Federal-State-Industry partnership sponsored by the Agency for Healthcare Research and Quality. The KID is a probability-based sample of pediatric stays from all hospitals that contribute data to HCUP. For each hospital, 10 percent of normal newborns and 80 percent of all other neonatal and pediatric stays are randomly selected. Weights are provided to allow the calculation of national estimates of hospitalizations in short-term, acute care hospitals (termed "community hospitals" by the American Hospital Association). Stays in specialized substance abuse and psychiatric facilities are excluded, but stays in psychiatric units within general hospitals are included. Information provided in the KID includes principal and secondary diagnoses, principal and secondary procedures, admission and discharge status, patient demographics (e.g., gender, age, race), total charges and length of stay. The KID is released every three years, and we used the years 2000, 2003, and 2006, the most recently available at the time [14]. The unit of analysis is a hospitalization, and it is possible that an individual patient contributes more than one hospitalization to the database in any given year. Hospitalizations are not linked by patient identifiers, and there is no way to analyze re-hospitalizations in this database.

HCUP uses the Clinical Classifications Software (CCS) tool for clustering patient diagnoses and procedures into a manageable number of clinically meaningful categories [15]. The Mental Health Substance Abuse Clinical Classification Software (CCS-MHSA) tool was integrated into the CCS in 2008, and we applied the CCS-MHSA software to the KID for 2000, 2003, and 2006 to report hospitalizations in their current classifications. We calculated national rates using weighted estimates derived from HCUP database for numerator data, and information from the US Census 2000, and population estimates for 2003 and 2006 for the denominators. The database offers the option of assessing hospitalizations by principal diagnosis or by any diagnosis, and each serves different purposes. The principal diagnosis is the condition which is the chief reason for the hospital stay, as determined after evaluation during the stay. To assess the overall burden of mood disorders we considered whether a child had any diagnosis of mood disorders. The CCS coding system assigns E codes (external cause of injury codes) to category 662, with the label "Suicide and Self-Inflicted Injury". The HCUP KID provides data on charges, the amount that hospitals billed for services. A ratio enabling calculation of costs is available for the 
2003 and 2006 KID, but not the 2000 KID; to compare data over the study years we used charge data. To compare proportions of hospitalizations with different mental health diagnoses we used only the principal diagnosis because children may have more than one mental health diagnosis. We did not calculate incidence by race or ethnic groups because of the well documented concerns about states that do not report race or ethnicity [16]. Following technical recommendations provided by AHRQ's HCUP resources, the SAS 9.2 procedure, SURVEYMEANS, was used to calculate weighted estimates, accounting for the HCUP KID sampling methodology and using Taylor series estimation for the confidence intervals [17-19].

\section{Results}

For each of the study years, information was available for over 2 million hospitalizations (unweighted) representing 6.3-6.5 million hospitalizations for children in the U.S., with fewer than $0.01 \%$ of cases missing information on diagnoses. In 2000, 2003 and 2006, the weighted number of hospitalizations of children under age 18 with a mental health principal diagnosis ranged from 145,024-160,252. The percentages of hospitalizations with a mental health principal diagnosis were $15.6 \%, 15.2 \%$, and $15.0 \%$ in children $10-14$ in the study years 2000, 2003, and 2006, and $15.2 \$, 14.5 \%$ and $13.7 \%$ in children $15-17$ in the same study years. For children age 5-9, hospitalizations with a mental health principal diagnosis accounted for $4.8 \%, 4.4 \%$ and $4.7 \%$ of pediatric hospitalizations in the three study years. For children age $1-4$, the percentages were $0.2 \%$ for each year.

Of the hospitalizations with a mental health principal diagnosis, 88,276 (55\%) in 2000, 92,349 (60\%) in 2003, and 86,251 (59\%) in 2006 had a principal diagnosis of mood disorders. The incidence of hospitalizations with mood disorders as the principal diagnosis (MHSA-CCS code 657$)$ was $12.4 / 10,000(95 \% \mathrm{CI}=12.1-12.7)$ in 2000 , $13.0 / 10,000$ in 2003 (95\% CI $=12.8-13.3)$, and $12.1 /$ $10,000$ (95\% CI $=11.9-12.2)$ in 2006. The incidence of hospitalizations with any diagnosis of mood disorders was $18.9 / 10,000$ (95\%. CI $=18.5-19.2)$ in $2000,20.4 /$
$10,000$ in 2003 (95\% CI $=20.1-20.6)$, and $19.6 / 10,000$ $(95 \% \mathrm{CI}=19.3-19.9)$ in 2006.

The CCS-MHSA system subdivides the group "Mood disorders" into two categories, "Bipolar disorders" and "Depressive disorders." At this level of classification, the incidence of hospitalizations for depressive disorders decreased from $9.1 / 10,000(95 \% \mathrm{CI}=8.8-9.3)$ in 2000 , to $8.4 / 10,000(95 \% \mathrm{CI}=8.3-8.6)$ in 2003 , and to $6.4 /$ $10,000(95 \% \mathrm{CI}=5.5-5.8)$ in 2006 , while the incidence of hospitalizations for bipolar disorders increased from $3.3 / 10,000(95 \% \mathrm{CI}=3.2-3.5)$ in 2000 to $4.6 / 10,000(95 \%$ $\mathrm{CI}=4.5-4.7)$ in 2003 and $5.7 / 10,000(95 \% \mathrm{CI}=5.5-5.8)$ in 2006 (Table 1).

At the most granular level, the category, "Mood disorders", includes 56 ICD-9-CM codes (Appendix 1). In 2006, the most frequent specific mood disorder diagnosis was "unspecified episodic mood disorder" (ICD-9CM 296.90) and accounted for $11.0 \%$ of the hospitalizations for mood disorders (Table 2). This was followed by depressive disorder not elsewhere classified (311) and manic-depressive not otherwise specified (296.80) which accounted for 10.3 and 8.4 percent of the hospitalizations, respectively. The eight most frequent specific diagnoses accounted for over $50 \%$ of the hospitalizations with a principal diagnosis of mood disorders.

The diagnosis of mood disorder was strongly associated with suicide attempt (or self-injurious behavior). Within children with any diagnosis of mood disorder, the percentage with a suicide attempt was $11.0 \%$ in $2000,10.2 \%$ in 2003 , and $9.7 \%$ in 2006 . Within children with no diagnosis of mood disorder, the percentage with a suicide attempt was $0.2 \%, 0.1 \%$ and $0.1 \%$ in the same study years. In 2000, children with any diagnosis of mood disorder were 73 times more likely to have a code of "suicide attempt" on their hospital record compared to children without a diagnosis of mood disorders, in 2003 they were 101 times as likely and in 2006 they were 122 times as likely.

The incidence of hospitalizations for mood disorders increased with age. In 2006, the incidence of hospitalizations with any diagnosis of mood disorders was 7.2/ 10,000 in children ages 5-11 and 47.1/10,000 in children

Table 1 Incidence of hospitalization per 10,000 and 95\% Confidence Intervals among children under 18, 2000-2006

\begin{tabular}{|c|c|c|c|}
\hline Diagnostic Category & 2000 & 2003 & 2006 \\
\hline Mood disorders as principal diagnosis & $\begin{array}{r}12.4 \\
(12.1-12.7)\end{array}$ & $\begin{array}{r}13.0 \\
(12.8-13.3) \\
\end{array}$ & $\begin{array}{r}12.1 \\
(11.9-12.2)\end{array}$ \\
\hline Mood disorders as all-listed diagnosis & $\begin{array}{r}18.9 \\
(18.5-19.2) \\
\end{array}$ & $\begin{array}{r}20.4 \\
(20.1-20.6) \\
\end{array}$ & $\begin{array}{r}19.6 \\
(19.3-19.9) \\
\end{array}$ \\
\hline Bipolar disorders as principal diagnosis & $\begin{array}{r}3.3 \\
(3.2-3.5)\end{array}$ & $\begin{array}{r}4.6 \\
(4.4-4.7)\end{array}$ & $\begin{array}{r}5.7 \\
(5.5-5.8)\end{array}$ \\
\hline Depressive disorders as principal diagnosis & $\begin{array}{r}9.1 \\
(8.8-9.3)\end{array}$ & $\begin{array}{r}8.4 \\
(8.3-8.6)\end{array}$ & $\begin{array}{r}6.4 \\
(5.5-5.8)\end{array}$ \\
\hline
\end{tabular}


Table 2 The leading ICD-9-CM diagnoses in children hospitalized with a principal diagnosis of mood disorder as a percentage of all hospitalizations with a principal diagnosis of mood disorder, 2006

\begin{tabular}{|c|c|c|}
\hline Diagnosis (ICD-9-CM code) ${ }^{1}$ & $\begin{array}{l}\text { CCS-MHSA } \\
\text { Sub-category }\end{array}$ & $\begin{array}{l}\text { Percentage of hospitalizations for mood } \\
\text { disorders and } 95 \% \mathrm{Cl} \text { of estimate }\end{array}$ \\
\hline Unspecified episodic mood disorder (296.90) & Bipolar & $11.0(10.8-11.3)$ \\
\hline Depressive disorder not elsewhere classified (311) & Depressive & $10.3(10.1-10.5)$ \\
\hline Manic-depressive not otherwise specified (296.80) & Bipolar & $8.4(8.2-8.6)$ \\
\hline Depressive affective disorders - unspecified (296.2) & Depressive & $6.6(6.4-6.8)$ \\
\hline Recurrent depressive disorder - severe (296.33) & Depressive & $5.4(5.3-5.7)$ \\
\hline Depressive psychosis -severe (296.23) & Depressive & $4.1(4.0-4.4)$ \\
\hline Recurrent depressive disorder - unspecified (296.30) & Depressive & $2.4(2.3-2.6)$ \\
\hline Bipolar affective disorder, most recent episode mixed - unspecified (296.60) & Bipolar & $2.3(2.2-2.6)$ \\
\hline
\end{tabular}

${ }^{1}$ The categorization of ICD-9 codes into sub-categories, Bipolar and Depressive, is shown in Appendix 1.

ages 12-17, and the incidence of hospitalizations with principal diagnosis of mood disorders was 4.4/10,000 and 29.0/10,000, respectively. The rate was less than $1.0 / 10,000$ in children under 4. Age specific rates show a sharp increase between age 12 and 17 , and a slight decline between age 17 and 18 (Figure 1). Among the hospitalizations with any diagnosis of mood disorder there were more females than males $(57 \%$ female in 2006).

Over the years 2000 to 2006, an increasing proportion of hospital stays for mood disorders was paid by the government (Table 3). Medicare and Medicaid were expected payers for $35 \%$ of cases in 2000, increasing to $45 \%$ in 2006 , and, correspondingly, the proportion paid by private insurance decreased from $57 \%$ to $45 \%$. Over the same period, teaching hospitals accounted for an increasingly greater proportion of the hospitalizations, from 52 to $63 \%$. The distribution of mood disorder hospitalizations by hospital size remained fairly constant (9$10 \%$ in small hospitals, $22-24 \%$ in medium hospitals,

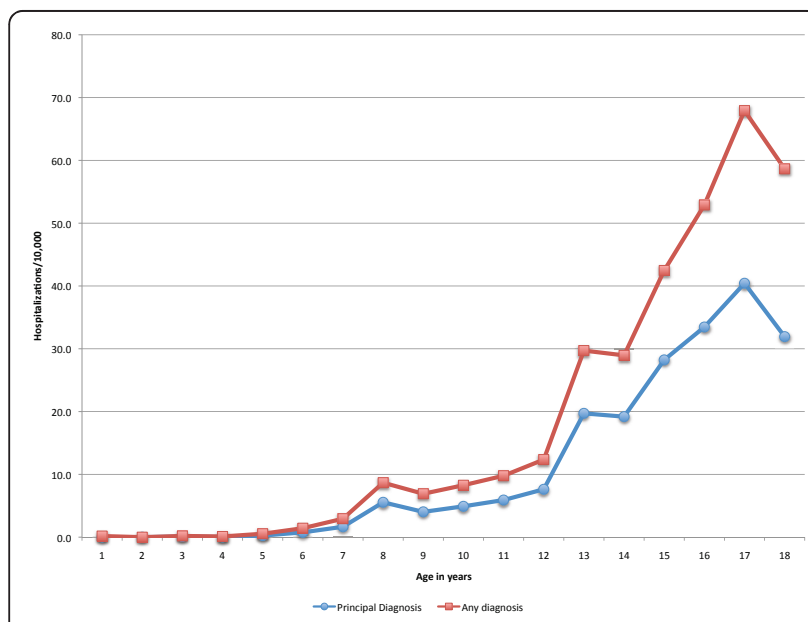

Figure 1 Pediatric hospitalizations with diagnoses of mood disorders, age specific rates/10,000 children 2006. and $68 \%$ in large hospitals over 2000-2006). Inflationadjusted charges for hospitalization increased from $\$ 10,600$ in 2000 , to $\$ 13,700$ in 2003 , to $\$ 16,300$ in 2006 , accompanied by a slight increase in length of stay from 7.1 days in 2000 to 7.7 days in 2006. The aggregate charges for hospitalizations with any diagnosis of mood disorders were over \$2.2 billion in 2006.

Hospitalization rates for children with a principal diagnosis of mood disorders varied several fold by region of the country. The western region of the United States experienced the lowest pediatric hospitalization rates for mood disorders, ranging from 9.9/10,000 to 11.6/10,000 during the 2000-2006 time period (Figure 2). In the same period, hospitalization rates for mood disorders ranged from $18.1 / 10,000$ to $21.9 / 10,000$ in the South and 19.0/ 10,000 to $21.2 / 10,000$ in the Northeast. Hospitalization rates for mood disorders in children were highest in the Midwest ranging from 25.4/10,000 to 27.6/10,000 children. Rates in the Midwest, Northeast and South were more than double the rates of the West. In the Midwest, the Relative Risk of admission to a hospital with a diagnosis of mood disorder was 2.7, 2.4 and 2.5 in the three study years. In the Northeast, these same Relative Risks were 2.1, 1.6 and 2.1, and in the South, the Relative Risks were $1.8,1.9$ and 2.1. In 2006, a similar pattern was observed for hospitalizations with any mental health diagnosis as a primary diagnosis with rates of 20.1/10,000 in the Midwest, 16.6/10,000 in the Northeast, and 16.5/ 10,000 in the South, all, higher than the $6.4 / 10,000$ observed in the West. Hospitalizations with any mental health diagnosis (primary or not) were $49.7 / 10,000$ in the Midwest, 51.6/10,000 in the Northeast, 48.5/10,000 in the South and 30.7/10,000 in the West. The regional variation in hospitalizations for mood disorders contrasts with the overall rates of pediatric hospitalizations by region for 2006. The highest hospitalization rates were found in the South $(1,004.4 / 10,000)$ followed by the Northeast $(891.4 / 10,000)$ and West $(862.1 / 10,000)$, and lowest in the Midwest $(788.1 / 10,000)$. 
Table 3 Characteristics of hospitalization among children under 18 with any mood disorder diagnosis, 2000-2006 ${ }^{1}$

\begin{tabular}{|c|c|c|c|}
\hline & 2000 & 2003 & 2006 \\
\hline \multicolumn{4}{|l|}{ Primary expected payer } \\
\hline Medicare or Medicaid & $35.1 \%$ & $40.2 \%$ & $45.2 \%$ \\
\hline Private & $56.5 \%$ & $49.7 \%$ & $45.3 \%$ \\
\hline Other & $8.4 \%$ & $9.8 \%$ & $9.5 \%$ \\
\hline \multicolumn{4}{|l|}{ Teaching status of hospital } \\
\hline Teaching & $51.7 \%$ & $58.3 \%$ & $62.8 \%$ \\
\hline Non-teaching & $48.4 \%$ & $41.7 \%$ & $37.2 \%$ \\
\hline \multicolumn{4}{|l|}{ Hospital size } \\
\hline Small & $9.1 \%$ & $10.1 \%$ & $10.4 \%$ \\
\hline Medium & $24.0 \%$ & $22.1 \%$ & $21.6 \%$ \\
\hline Large & $66.9 \%$ & $67.7 \%$ & $68.0 \%$ \\
\hline Average Length of Stay and 95\% Confidence Intervals in days & $\begin{array}{r}7.0 \\
(6.9-7.1)\end{array}$ & $\begin{array}{r}7.1 \\
(7.0-7.2)\end{array}$ & $\begin{array}{r}7.6 \\
(7.5-7.7)\end{array}$ \\
\hline Mean total charges $^{2}$ & $\$ 10,578$ & $\$ 13,676$ & $\$ 16,287$ \\
\hline
\end{tabular}

The mean age ranged from 13.9 in the South to 14.5 in the West. In 2006, the rates of hospitalizations for females and males followed the regional pattern; females and males from the Midwest had the highest rates and their counterparts from the West had the lowest rates of hospitalization with any diagnosis of mood disorder. The proportion paid by Medicare or Medicaid ranged from $31.2 \%$ in the West to $51.8 \%$ in the South, and the proportion paid by private insurance ranged from $38.3 \%$ in the South to $56.5 \%$ in the West. Mean total charges in 2006 were lowest in the Midwest $(\$ 12,260)$ and highest in the West $(\$ 23,980)$. The average length of stay was lowest in the Midwest (6.5 days) and highest in the Northeast (10.4 days).

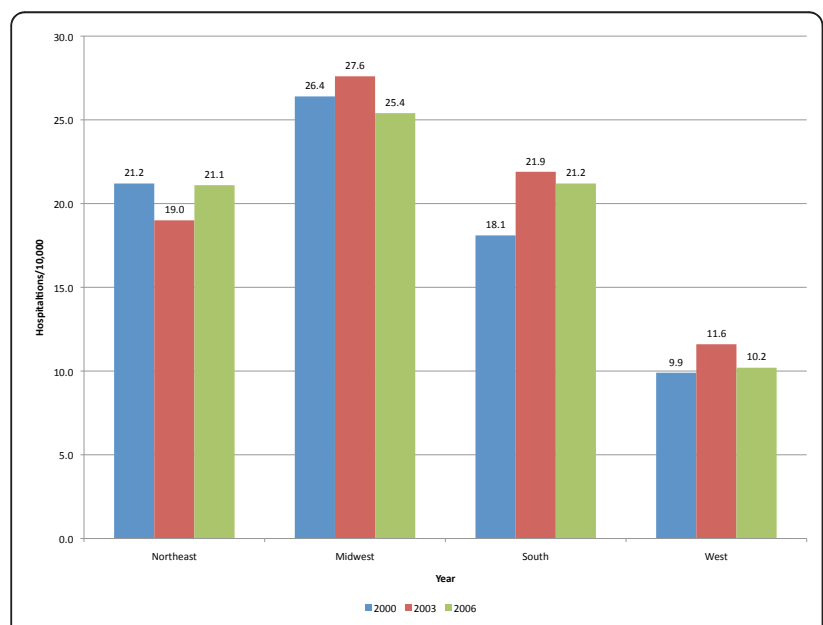

Figure 2 Hospitalization rates with any diagnosis of mood disorders by region $2000-2006$.

\section{Discussion}

The population rate of pediatric acute hospitalizations with a principal discharge diagnosis of mood disorder remained relatively stable from $2000(12.4 / 10,000)$ through $2006(12.1 / 10,000)$, even though the total number of hospitalizations increased in concert with the increase in the U.S. population. Although the 95\% confidence intervals for the 2000, 2003 and 2006 estimates are extremely narrow and the difference in rates are statistically significant at the level of alpha $=0.05$, the differences in rates are small and may not be significant from a clinical or public health perspective.

When the broad category of mood disorders is broken into the sub-categories of bipolar and depressive disorders two different patterns emerge. There was an increase in the rate of hospitalization with a principal diagnosis of bipolar disorders from 3.3/10,000 in 2000 to $5.5 / 10,000$ children in 2006 , and a concomitant decrease in hospitalizations with a principal diagnosis of depressive disorder from $8.9 / 10,000$ to $6.2 / 10,000$ from 2000 to 2006. In this database, the use of bipolar disorder diagnoses may be replacing the use of depressive disorder diagnoses, resulting in a relatively constant incidence of mood disorders hospitalizations over the time period, but further study may be required to explain these trends. A study of a similar data set in an earlier time period found admissions for both bipolar and depressive disorders to increase as a proportion of mental health admissions to community hospitals from 1990-2000, but did not calculate hospitalization rates relative to the denominator of children in the population [11]. Another study of hospital discharges in the US reported increases in both diagnoses as a proportion 
of psychiatric hospitalizations, and reported population based rates for the bipolar diagnoses only [20]. A study of outpatient office visits showed an increase in diagnosis and treatment of bipolar disorders between19941995 and 2002-2003, but did not report on depressive disorders [2]. In contrast to our findings, researchers studying hospitalizations in Germany between 2000 and 2007 found increase in population-based admission rates for both bipolar and depressive disorders [21].

When considering specific ICD-9-CM diagnoses, the three most frequently used diagnoses were "other and unspecified episodic mood disorder", "depressive disorder not elsewhere classified" and "manic-depressive not otherwise specified". Mood disorder hospitalizations were strongly linked to "suicide attempts", although at least a fourth of hospitalizations for suicide attempts and self-injurious behavior did not have a discharge diagnosis of mood disorder. This can be explained by the fact that suicidal behavior can occur in contexts other than mood disorder, such as personality disorders, substance abuse, or adjustment disorders [3]. The proportion of mood disorder hospitalizations paid by the government as well as the increasing trend between 2000 and 2006 is similar to that observed for all pediatric hospitalizations in this data set, $37 \%, 41 \%$ and $44 \%$, respectively.

We found substantial regional variation in the rate of pediatric hospitalizations with a mood disorder diagnosis; in 2006, the rate was 2.5 times higher in the Midwest, 2.1 times higher in the Northeast and 1.8 times higher in the South than in the West. The regional differences were observed for all study years, 2000, 2003, and 2006. This finding is consistent with previous research showing a high proportion of mental health hospitalizations in the Midwest and the lowest proportion occurring in the West [11]. Our data go beyond the earlier analysis by using the hospitalization data to calculate population based rates. Other aspects of mental health care utilization have been examined by region, but do not supply ready explanations for the difference in hospitalization rates that we observed. Geographic variation in ambulatory care use (physician, other provider and emergency department visits) has been reported in adults for mental health/substance abuse, average spending and percentage paid out of pocket, showing the highest use in the Northeast and Midwest [22]. No statistically significant regional differences in antidepressant use in children and adolescents have been reported $[23,24]$. In contrast, Doshi and colleagues (2005) found rates of emergency department visits for suicide attempt or self-inflicted injury to be lowest in the Midwest, and highest in the West and Northeast, but the 95\% confidence intervals of the estimates were wide and overlapping [25]. Their population ranged in age from under
14 to over 50 , with a mean age of 31 , and they did not analyze the regional data by age sub-groups. Blanco et al. (2008) estimated the prevalence of psychiatric disorders in college age youth to range from $41 \%$ in the Northwest to 53\% in the Midwest [26].

It is difficult to compare our regional data to those from previous studies, because of differences in definitions, populations, and measures, and to explain the regional differences we observed in hospitalization rates without further detailed analyses of the underlying distribution of mood and mental health disorders, practice patterns, bed availability (including distribution of psychiatric hospitals), insurance policies, and other organizational factors that may affect hospitalization rates. In the HCUP KID, other mental health diagnoses appear to be higher in the Midwest and lower in the West, but general pediatric hospitalizations do not follow this pattern.

The strengths of this analysis lie in the large database, the probability based sampling, and the standardized methodology of the tri-annual data. As with other administrative measures of disease, hospital discharge diagnoses are subject to misclassification, and may either under- or over-estimate a given condition. Misclassification might also apply to other variables, such as suicidal behavior. One of the limitations is the lack of information about specific hospital units such as psychiatric or pediatric acute care units. The observation of hospitalizations for poisonings categorized as "suicide attempts", but without the diagnosis of mood disorders deserves further analysis to ascertain that mood disorders were not present, resulting in an underestimate of the true rate. Furthermore, the HCUP KID database does not include hospitalizations in psychiatric hospitals, substance abuse facilities, and rehabilitation hospitals (both long term and short term) and our analyses thus underestimate population rates of hospitalization for mood disorders. It is also possible that trends in hospitalization rates to psychiatric hospitals for mood disorders show differing patterns than that observed in general hospitals, but it does not detract from a central point, that large amounts of resources in general hospitals are being used to address mood disorders in children under 18 in the United States. These data have internal validity for inferences made about mood disorder hospitalizations in the United States between 2000-2006, but may not allow inferences to hospitalizations in psychiatric hospitals in the United States, and may not be generalizable outside of the United States.

\section{Conclusions}

Mood disorders are a major reason for hospitalization during development, especially in adolescence. The 
mood disorder hospitalization rate remained relatively constant from 2000-2006, but with a decrease in the rate of depressive disorders hospitalizations and an increase in the rate of bipolar disorders hospitalizations. These data underscore the prominent burden of mood disturbances on the health of children and especially adolescents, trends in cost and utilization, the increasing burden on public resources, and regional variation. While we were unable to explain the regional variation in utilization of mental health inpatient care, we demonstrated variation that persisted over the study years 2000-2006. The data point to the need, on one hand, to provide inpatient specialized care for pediatric mood disorders, and, on the other hand, to develop more effective interventions to prevent or treat these conditions in the community thus decreasing the need for hospitalization.

\section{Appendix 1}

The single level CCS-MHSA category, 657, Mood disorders, and the ICD-9 codes that comprise the multilevel categories, Bipolar disorders, and Depressive disorders.

Bipolar

296.00 MANIC DISORDER-UNSPECIFIED

296.01 MANIC DISORDER-MILD

296.02 MANIC DISORDER-MODERATE

296.03 MANIC DISORDER-SEVERE

296.04 MANIC DISORDER-SEVERE WITH PSYCHOTIC BEHAVIOR

296.05 MANIC DISORDER - PARTIAL REMISSION

296.06 MANIC DISORDER - FULL REMISSION

296.10 RECURRENT MANIC DISORDERUNSPECIFIED

296.11 RECURRENT MANIC DISORDER-MILD

296.12 RECURRENT MANIC DISORDERMODERATE

296.13 RECURRENT MANIC DISORDER-SEVERE

296.14 RECURRENT MANIC DISORDER-SEVERE WITH PSYCHOTIC BEHAVIOR

296.15 RECURRENT MANIC DISORDER-PARTIAL REMISSION

296.16 RECURRENT MANIC DISORDER-FULL REMISSION

296.40 BIPOLAR AFFECTIVE DISORDER MANICUNSPECIFIED

296.41 BIPOLAR AFFECTIVE DISORDER MANIC-

MILD

296.42 BIPOLAR AFFECTIVE DISORDER MANICMODERATE

296.43 BIPOLAR AFFECTIVE DISORDER MANICSEVERE
296.44 BIPOLAR MANIC-SEVERE WITH PSYCHOTIC BEHAVIOR

296.45 BIPOLAR AFFECTIVE DISORDER MANICPART REMISSION

296.46 BIPOLAR AFFECTIVE DISORDER MANICFULL REMISSION

296.50 BIPOLAR AFFECTIVE DISORDER DEPRESSED-UNSPECIFIED

296.51 BIPOLAR AFFECTIVE DISORDER DEPRESSED-MILD

296.52 BIPOLAR AFFECTIVE DISORDER DEPRESSED-MODERATE

296.53 BIPOLAR AFFECTIVE DISORDER DEPRESSED-SEVERE

296.54 BIPOLAR DEPRESSED-SEVERE WITH PSYCHOTIC BEHAVIOR

296.55 BIPOLAR AFFECTIVE DEPRESSED-PARTIAL REMISSION

296.56 BIPOLAR AFFECTIVE DEPRESSED-FULL REMISSION

296.60 BIPOLAR AFFECTIVE DISORDER MIXED-

UNSPECIFIED

296.61 BIPOLAR AFFECTIVE DISORDER MIXED-

MILD

296.62 BIPOLAR AFFECTIVE DISORDER MIXEDMODERATE

296.63 BIPOLAR AFFECTIVE DISORDER MIXEDSEVERE

296.64 BIPOLAR MIXED-SEVERE With PSYCHOTIC BEHAVIOR

296.65 BIPOLAR AFFECTIVE DISORDER MIXPARTIAL REMISSION

296.66 BIPOLAR AFFECTIVE DISORDER MIXFULL REMISSION

296.7 BIPOLAR AFFECTIVE NOT OTHERWISE SPECIFIED

296.80 MANIC-DEPRESSIVE NOT OTHERWISE SPECIFIED

296.81 ATYPICAL MANIC DISORDER

296.82 ATYPICAL DEPRESSIVE DISORDER

296.89 MANIC-DEPRESSIVE NOT ELSEWHERE CLASSIFIED

296.90 UNSPECIFIED EPISODIC MOOD DISORDER

296.99 AFFECTIVE PSYCHOSES NOT ELSEWHERE CLASSIFIED

Depressive

293.83 ORGANIC AFFECTIVE SYNDROME

296.20 DEPRESSIVE AFFECTIVE DISORDERSUNSPECIFIED

296.21 DEPRESSIVE AFFECTIVE DISORDERMILD 


\author{
296.22 DEPRESSIVE AFFECTIVE DISORDER- \\ MODERATE \\ 296.23 DEPRESSIVE AFFECTIVE DISORDER- \\ SEVERE WITHOUT PSYCHOTIC BEHAVIOR \\ 296.24 DEPRESSIVE AFFECTIVE DISORDER- \\ SEVERE WITH PSYCHOTIC BEHAVIOR \\ 296.25 DEPRESSIVE AFFECTIVE DISORDER-PAR- \\ TIAL REMISSION \\ 296.26 DEPRESSIVE AFFECTIVE DISORDER- \\ FULL REMISSION \\ 296.30 RECURRENT DEPRESSIVE DISORDER- \\ UNSPECIFIED \\ 296.31 RECURRENT DEPRESSIVE DISORDER- \\ MILD \\ 296.32 RECURRENT DEPRESSIVE DISORDER- \\ MODERATE \\ 296.33 RECURRENT DEPRESSIVE DISORDER- \\ SEVERE \\ 296.34 RECURRENT DEPRESSIVE DISORDER- \\ SEVERE WITH PSYCHOTIC BEHAVIOR \\ 296.35 RECURRENT DEPRESSIVE DISORDER- \\ PARTIAL REMISSION \\ 296.36 RECURRENT DEPRESSIVE DISORDER- \\ FULL REMISSION \\ 3004 NEUROTIC DEPRESSION \\ 311 DEPRESSIVE DISORDER NOT ELSE- \\ WHERE CLASSIFIED
}

\section{Acknowledgements}

Funds for data analysis by research assistant, Aliza Krieger, were provided by the University of Rhode Island in the summer of 2009.

\begin{abstract}
Author details
${ }^{1}$ MIE Resources, Kingston, Rhode Island, USA. ${ }^{2}$ Zambarano Unit, Eleanor Slater Hospital, Cranston, Rhode Island, USA. ${ }^{3}$ Center for Delivery, Organization, and Markets, Agency for Healthcare Research and Quality, Rockville, MD, USA. ${ }^{4}$ Child \& Adolescent Treatment \& Preventive Intervention Research Branch, National Institute of Mental Health, Bethesda, MD, USA.
\end{abstract}

\section{Authors' contributions}

All authors contributed to discussion and interpretation of data analysis, and writing and revisions of the manuscript. TL identified the research question, provided epidemiologic expertise, and led the analysis and manuscript preparation. AK conducted the SAS programming for the data analysis and provided expertise in clinical psychology. AE provided expertise on HCUP KID and data analysis of HCUP KID. BV provided expertise on psychiatry and mental health in children.

\section{Competing interests}

The authors declare that they have no competing interests.

Received: 22 March 2011 Accepted: 7 August 2011

Published: 7 August 2011

\section{References}

1. Merikangas KR, Kalaydjian A: Magnitude and impact of comorbidity of mental disorders from epidemiologic surveys. Curr Opin Psychiatry 2007, 20:353-358.
2. Moreno C, Laje G, Blanco C, Jiang H, Schmidt AB, Olfson M: National trends in the outpatient diagnosis and treatment of bipolar disorder in youth. Archives of general psychiatry 2007, 64:1032-1039.

3. Foley D, Goldston D, Costello EJ, Angold A: Proximal psychiatric risk factors for suicidality in youth: The Great Smokey Mountains Study. Archives of general psychiatry 2006, 62:1017-1024

4. Kessler RC, Avenevoli S, Ries Merikangas K: Mood disorders in children and adolescents: an epidemiologic perspective. Biol Psychiatry 2001, 49:1002-1014.

5. Merikangas KR, He JP, Burstein M, Swanson SA, Avenevoli S, Cui L, Benjet C, Georgiades K, Swendsen J: Lifetime prevalence of mental disorders in U.S. adolescents: results from the National Comorbidity Survey ReplicationAdolescent Supplement (NCS-A). J Am Acad Child Adolesc Psychiatry 2010, 49:980-989.

6. Agency for Healthcare Research and Quality: Care of Children and Adolescents in US Hospitals HCUP Fact Book No. 4. Book Care of Children and Adolescents in US Hospitals HCUP Fact Book No 4 (Editor ed^eds) City: Agency for Healthcare Research and Quality; 2003.

7. Healthcare Cost and Utlization Project (HCUP).

8. US Department of Health and Human Services: Mental Health: A Report of the Surgeon General. Book Mental Health: A Report of the Surgeon General (Editor ed^eds) City: US Public Health Service; 1999

9. Mark L, Levit K, Coffey R, Kusick D, Harwood H, King E, Bouchery E, Genuardi J, Vandivort-Warre R, Buck J, Ryan K: National Expenditures for Metal Health Services and Substace Abuse Treatment, 1993-2003. Book National Expenditures for Metal Health Services and Substace Abuse Treatment, 1993-2003 (Editor ed^eds) City: Substance Abuse and Mental Health Services Administration; 2007.

10. Pottick K, McAlpine D, Andelman R: Changing Patterns of Psychiatric Inpatient Care for Children and Adolescents in General Hospitals, 19881995. Am J Psychiatry 2000, 157:1267-1273.

11. Case BG, Olfson M, Marcus SC, Siegel C: Trends in the inpatient mental health treatment of children and adolescents in US community hospitals between 1990 and 2000. Archives of general psychiatry 2007, 64:89-96.

12. Mandell DS, Thompson WW, Weintraub ES, Destefano F, Blank MB: Trends in diagnosis rates for autism and ADHD at hospital discharge in the context of other psychiatric diagnoses. Psychiatr Serv 2005, 56:56-62.

13. Olfson M, Gameroff MJ, Marcus SC, Greenberg T, Shaffer D: National trends in hospitalization of youth with intentional self-inflicted injuries. Am J Psychiatry 2005, 162:1328-1335.

14. Agency for Healthcare Research and Quality: HCUP Kids' Inpatient Database (KID) Healthcare Cost and Utilization Project (HCUP) 2000,2003, 2006. Book HCUP Kids' Inpatient Database (KID) Healthcare Cost and Utilization Project (HCUP) 2000,2003, 2006 (Editor ed^eds) City 2006.

15. Elixhauser A, Steiner C, Palmer L: Clinical Classifications Software (CCS). Book Clinical Classifications Software (CCS) (Editor ed^eds) City: Agency for Healthcare Research and Quality; 2008.

16. Coffey R, Barrett M, Houchens R, Moy E, Andrews R: Methods Applying AHRQ Quality Indicators to Healthcare Cost and Utilization Project (HCUP) Data for the Fifth (2007) National Healthcare Disparities Report. Book Methods Applying AHRQ Quality Indicators to Healthcare Cost and Utilization Project (HCUP) Data for the Fifth (2007) National Healthcare Disparities Report (Editor ed^eds) City: US Agency for Healthcare Research and Quality; 2007.

17. SAS Institute Inc: SAS/STAT 9.2 User's Guide. Cary, North Carolina; 2008.

18. HCUP Online Tutorial Resource: National Estimates Example Code and Output. [http://www.hcup-us.ahrq.gov/tech_assist/nationalestimates/ Interactive/resources/National_Estimates_Example_Code_and_Output.pdf].

19. Agency for Healthcare Research and Quality: National Healthcare Quality Report. Book National Healthcare Quality Report (Editor ed^eds) City: US Department of Health and Human Seervices; 2009.

20. Blader JC, Carlson GA: Increased rates of bipolar disorder diagnoses among U.S. child, adolescent, and adult inpatients, 1996-2004. Biol Psychiatry 2007, 62:107-114.

21. Holtmann M, Duketis E, Poustika L, Zepf F, Poustka F, Bolte S: Bipolar disorder in children and adolescents in Germany: national trends in the rates of inpatients, 2000-2007. Bipolar Disord 2010, 12:155-163.

22. Zuvekas $\mathrm{SH}$ : Prescription drugs and the changing patterns of treatment for mental disorders, 1996-2001. Health Aff (Millwood) 2005, 24:195-205. 
23. Vitiello B, Zuvekas SH, Norquist GS: National estimates of antidepressant medication use among U.S. children, 1997-2002. J Am Acad Child Adolesc Psychiatry 2006, 45:271-279.

24. Kurian B, Ray W, Arbogast P, Fuchs D, Dudley J, Cooper W: Effect of regulatory warnings on antidepressant prescribing for children and adolescents. Arch Pediatr Adolesc Med 2007, 161:690-696.

25. Doshi A, Boudreaux ED, Wang N, Pelletier AJ, Camargo CA Jr: National study of US emergency department visits for attempted suicide and self-inflicted injury, 1997-2001. Annals of emergency medicine 2005, 46:369-375.

26. Blanco C, Okuda M, Wright C, Hasin DS, Grant BF, Liu SM, Olfson M: Mental health of college students and their non-college-attending peers: results from the National Epidemiologic Study on Alcohol and Related Conditions. Archives of general psychiatry 2008, 65:1429-1437.

doi:10.1186/1753-2000-5-27

Cite this article as: Lasky et al:: Children's hospitalizations with a mood disorder diagnosis in general hospitals in the united states 2000-2006. Child and Adolescent Psychiatry and Mental Health 2011 5:27.

\section{Submit your next manuscript to BioMed Central} and take full advantage of:

- Convenient online submission

- Thorough peer review

- No space constraints or color figure charges

- Immediate publication on acceptance

- Inclusion in PubMed, CAS, Scopus and Google Scholar

- Research which is freely available for redistribution

Submit your manuscript at www.biomedcentral.com/submit
C BioMed Central 